\section{Edycaçäa

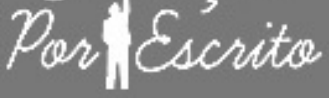

ARTIGO

\title{
Contextos emergentes na UFSM: a expansão da pós-graduação
}

\author{
Emerging contexts at ufsm: the post-graduation expansion
}

\author{
Silvana Zancana, Doris Pires Vargas Bolzan
}

\section{Editores}

Maria Inês Côrte Vitoria PUCRS, RS, Brasil Pricila Kohls dos Santos PUCRS, RS, Brasil

\section{Equipe Editorial}

Rosa Maria Rigo

PUCRS, RS, Brasil

\section{ISSN 2179-8435}

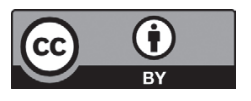

Este artigo está licenciado sob forma de uma licença Creative Commons Atribuição 4.0 Internacional, que permite uso irrestrito, distribuiçäo e reprodução seja corretamente citada http://creativecommons.org/licenses/by/4.0/deed.pt_BB

\section{RESUMO}

Esta pesquisa objetiva reconhecer a expansão da pós-graduação da Universidade Federal de Santa Maria (PPGs/ UFSM) em contextos emergentes, no período de 1970 a 2016. Trata-se de um estudo de caráter exploratório, de natureza qualitativa, com análise de dados de forma qualitativa e quantitativa. Por meio deste estudo, foi constatado que a linha de crescimento dos PPGs da UFSM se manteve em ascensão nas últimas décadas. Muitos foram os fatores implicados essa expansão, considerando o cenário de políticas externas e internas que contribuíram para o seu crescimento, como a nova filosofia do Plano de Gestão 2014-2017 da UFSM e o envolvimento de comissões internas dos PPGs, no sentido de manter e fortalecer a qualidade dos cursos. Além da discussão a respeito de políticas que antecedam a avaliação externa da Capes. A participação da cooperação internacional e nacional potencializa experiências de outros PPGs e desenvolve padrões internos de ensino e pesquisa na UFSM, bem como promove o intercâmbio de pessoas a outros países, recebendo também estrangeiros nos PPGs da UFSM. Para os próximos anos, a expectativa é que o crescimento dos PPGs da UFSM seja mínimo, considerando as políticas criteriosas da Capes e o objetivo da UFSM de garantir e promover a qualidade dos cursos.

Palavras-chave: Expansão; Pós-graduação da UFSM; Contextos emergentes; Stricto sensu.

\section{ABSTRACT}

This research aims to recognize the expansion of the Postgraduate Program at Universidade Federal de Santa Maria (PPGs/UFSM) in emerging contexts in the period from 1970 to 2016 . This is an exploratory study of a qualitative nature, with qualitative and quantitative data analysis. Looking at its expansion in emerging contexts, it has been observed that the growth line of the UFSM PPGs has continued to rise in the last decades. There were

\footnotetext{
a Doutoranda em Educação pelo Programa de Pós-Graduação em Educação da Universidade Federal de Santa Maria (PPGE/UFSM). Mestre em Educação. Especialista em Educação Física Escolar pelo CEFD/UFSM.

b Doutora em Educação, docente do Centro de Educação da Universidade Federal de Santa Maria, Santa Maria, RS, Brasil.
} 
many factors that led to the UFSM PPGs expansion, in view of the scenario of external and internal policies that promoted growth, such as: the UFSM new philosophy of the Management Plan 2014-2017, as well as the PPGs involvement of internal committees, in order to maintain and strengthen the quality of the courses, as well arguing policies that precede the external evaluation of Capes. The international and national participation of cooperation, in order to enhance the experiences of other PPGs and to develop internal standards of teaching and research in UFSM; The exchange of people to other countries, as well as receiving foreigners in UFSM PPGs. The expectation for the coming years implies that the growth of UFSM PPGs is minimal, considering the rigorous policies of Capes and the objective of guaranteeing and promoting the quality of courses at UFSM.

Keywords: Expansion; UFSM post-graduation; Emerging contexts; Stricto sensu.

\section{Introdução}

$\mathrm{O}$

estudo aqui apresentado deriva da pesquisa de doutoramento "Professor pesquisador: docência em contextos emergentes", que tem como elo o projeto "Docência e processos formativos: estudantes e professores em contextos emergentes"1, pesquisa em andamento do Grupo Formação de Professores e Práticas Educativas: Educação Básica e Superior - GPFOPE ${ }^{2}$. A pesquisa de doutorado busca compreender que saberes são necessários ao professor pesquisador, para que desenvolva sua atividade em contextos emergentes. Assim, este artigo é um desdobramento do cenário da educação superior e pós-graduação, com enfoque nos relatos históricos da pós-graduação na UFSM e sua expansão em contextos emergentes na universidade, colocando em destaque os campos nos quais ela se evidencia.

Assim, parte-se da discussão dos contextos emergentes da pós-graduação e suas implicações no cenário da pósgraduação da UFSM, desde sua criação até o ano de 2016, para assim demonstrar os caminhos que levaram à sua

\footnotetext{
1 A temática deste projeto de pesquisa "Docência e processos formativos: estudantes e professores em contextos emergentes" tem como foco aprofundar a compreensão relativa à docência e aos processos formativos dos estudantes e professores formadores das licenciaturas e professores em formação continuada na educação básica, em contextos emergentes. O projeto teve seu início em 1으 de janeiro de 2016 e será concluído em 31 de dezembro de 2020.

2 Grupo de Pesquisa Formação de Professores e Práticas Educativas: Educação Básica e Superior (GPFOPE). Investiga em seus estudos e pesquisas temáticas relativas à aprendizagem da docência em diferentes níveis de ensino e suas práticas, desdobrando-se em duas linhas de pesquisa: formação docente e práticas educativas no Ensino Básico; formação docente e desenvolvimento profissional no Ensino Superior.
} 
expansão nessa universidade. Considera-se que os contextos emergentes versam sobre a lógica dos impactos que a Instituições de Ensino Superior vêm recebendo e sobre os discursos produzidos em tom de mudança e adaptação às novas demandas sociais e econômicas que emergem da implantação de políticas públicas.

Estudar a história da pós-graduação é um grande desafio para a comunidade acadêmica, pois retrata um cenário de evoluções da ciência e da vida de um povo. Também marca os anseios de uma época, de um grupo de pessoas e de evoluções de políticas públicas voltadas à inserção de uma prática científica de qualidade nas grandes áreas do saber.

Muitas reformas vêm acontecendo desde o final do século XX e início do século XXI, destacando-se a educação em relação à expansão do sistema educacional superior brasileiro, devido às tendências globais e neoliberais que implicam impactos nos cursos de pós-graduação.

Nesse sentido, o Ministério da Educação criou vários programas como meio de garantir a qualidade, o ingresso e a permanência de universitários em todas as regiões do Brasil, observando as ações da Unesco para desmistificar um quadro que aloca a universidade como um espaço elitizado. Aos olhos dessa organização, a educação é elementochave para o desenvolvimento sustentável, visto que corrobora e qualifica a capacidade humana para fazer suas próprias concepções sociais, considerando a qualidade do espaço a ser vivido.

No Brasil, como no mundo, a segunda metade do século XX foi marcada por uma expansão sem precedentes da demanda e da oferta de cursos de educação superior, ligadas tanto à valorização do saber acadêmico pelo mercado de trabalho quanto ao crescimento da importância da pesquisa acadêmica (MEC/Sesu, 2012). Assim, as iniciativas políticas tomadas pelo governo brasileiro buscam, mais especificamente, sanar as fragilidades encontradas na educação superior, quanto à sua expansão, qualidade e democratização, sinalizando reflexos dessa conjuntura na pós-graduação.

Pedrini (2011) destaca que, no século XXI, as mudanças foram marcadas pelas tessituras sociais, políticas, econômicas e culturais que se refletem cotidianamente em todos os segmentos da sociedade, de forma especial no ensino, para acompanhar as complexas transformações da sociedade.

De tal modo, pode-se afirmar que tanto a pós-graduação como a educação superior vivem um momento único no contexto social, histórico e econômico mundial. Muitos são os desafios a enfrentar na universidade, pautados nas ações que sinalizam a busca da qualidade do quadripé ensino, pesquisa, extensão e gestão, tendo em vista contemplar as novas demandas locais em um contexto global. Diante dessas mudanças, Bolzan (2016, p.9) ressalta que:

O movimento de expansão da educação brasileira em contextos emergentes, por meio da inclusão da diversidade de sujeitos/pessoas/indivíduos, lança-nos novas exigências, o que se reflete em todos os níveis dos sistemas de ensino. Os sujeitos que participam desses contextos experimentam novos espaços/tempos socioculturais, marcados pelas novas profissões e demandas em contextos globalizados. 
São essas mudanças e transações globais, que vêm ocorrendo na educação superior e na pós-graduação, que exigem das instituições novas reformulações, tanto em nível institucional como organizacional dos cursos e do corpo docente, que denomina-se de contextos emergentes. Esses "novos desafios, atualizações e reconfigurações se fazem necessários para que a universidade e a escola básica sejam capazes de desenvolver processos formativos compatíveis com os novos sujeitos, em novos contextos, na contemporaneidade" (BOLZAN, 2016, p. 9).

Desse modo, torna-se emergente falar de políticas públicas e ações do Ministério da Educação do Brasil, para acompanhar essa transição da educação superior e da pós-graduação, considerando que a inovação em ciência e tecnologia seja uma iniciativa buscada para a qualidade da educação de maneira mais ampla.

Assim, com o decorrer do tempo, novos olhares estão sendo lançados para a pós-graduação no Brasil, o que vem sendo foco de estudos para compreender as mudanças ocorridas na sociedade e de que forma os cursos lato sensu e stricto sensu estão voltados para os interesses sociais, políticos, tecnológicos e para a evolução da ciência.

\section{Metodologia}

O estudo vincula-se a uma abordagem metodológica de caráter exploratório de natureza qualitativa, que derivou de um mapeamento do campo de pesquisa e utilizou documentos como método investigativo. Foram consultados documentos do site da UFSM, da PROGEP/UFSM e da Plataforma Sucupira. Os dados foram analisados de forma qualitativa e quantitativa, no período de 1970 a 2016, a fim de compreender a expansão da pós-graduação dessa instituição em contextos emergentes. Permitiu, dessa forma, contrastar com as políticas externas da Capes e do CNPQ.

A pesquisa exploratória visou a realizar o mapeamento da pós-graduação da UFSM, a fim de reconhecer esse cenário e descobrir como os programas foram se desenvolvendo e quais os critérios que implicaram a sua evolução ao longo do tempo. Segundo Severino (2007, p. 123-4), "a pesquisa exploratória busca apenas levantar informações sobre um determinado objeto, delimitando assim um campo de trabalho, mapeando as condições de manifestação desse objeto".

Por isso, a pesquisa exploratória articulada aos estudos qualitativos permite, além de reconhecer o contexto, compreendê-lo e, por meio do olhar do investigador, trazer uma riqueza maior de detalhes quanto à realidade estudada. Entende-se que a abordagem qualitativa na área da Educação vem desvelando um novo conhecimento ao pesquisador, a partir da compreensão de que uma pesquisa é, pois, assumir a perspectiva da aprendizagem como processo social, compartilhado e gerador de desenvolvimento (FREITAS, 2002).

Em sua tese, Vygotski (1991) entende que toda cultura repercute no modo como o homem se organiza, comunica-se e aceita esses valores, tomando consciência de seu desenvolvimento e interação com o meio. Concluindo-se, 
sob essa perspectiva, que a internalização de atividades e comportamentos é reconstruída pelas ações e valores de uma dada cultura e dos meios externos que influenciam nessas mudanças.

Assim, a pesquisa exploratória e qualitativa irá construir a teia de informações e descrições acerca da história, da cultura e dos aspectos sociais do que se pretende investigar na expansão da pós-graduação da UFSM em contextos emergentes. Diante disso, a escolha da dimensão qualitativa justifica-se como aquela que "[...] se desenvolve numa situação natural, é rica em dados descritivos e tem um plano aberto e flexível e focaliza a realidade de forma complexa e contextualizada" (LUDKE e ANDRÉ, 1986, p. 18).

Para obter a compreensão desse campo investigativo, foi necessário recorrer aos documentos que estabeleceram as normas e os critérios para os programas de pós-graduação da instituição, objeto de pesquisa. Os documentos, como salienta May (2004), representam o reflexo da realidade, tornando-se um meio através do qual o pesquisador procura uma correspondência entre a sua descrição e os eventos aos quais esta se refere. Dessa forma, foi realizada uma análise ampla e atenta, de modo a alcançar toda a documentação concernente, demandando diversas leituras dos documentos consultados.

A análise de dados, pautada na abordagem quantitativa, abrange "um conjunto de procedimentos, técnicas e algoritmos destinados a auxiliar o pesquisador a extrair de seus dados subsídios para responder à(s) pergunta(s) que o mesmo estabeleceu como objetivo(s) de seu trabalho" (GATTI, 2004, p. 14). Essa visão quantitativa, aliada à análise qualitativa, permite construir um desenho do cenário e um olhar para as variáveis apresentadas, em consonância com a realidade e, a partir desta, descortinar os caminhos a serem explorados, articulando os saberes teóricos ao campo de dados.

\section{A Pós-Graduação da UFSM}

O desenvolvimento da história da pós-graduação da UFSM iniciou-se com a Resolução no 0016, de 29 de agosto de $1994^{3}$, que dispõe sobre a processualística para a criação de cursos de pós-graduação em nível de mestrado e doutorado stricto sensu, de modo que essa legislação interna ${ }^{4}$ retrata como tudo foi sendo articulado, organizado e gestado.

$3 \mathrm{O}$ art. 4o A montagem de Projeto de criação de curso, e que somente será concedida a autorização pela Pró-Reitoria de Pós-Graduação e Pesquisa, se os pareceres técnicos forem favoráveis. No Art. 5o O projeto de criação de Curso de Pós-Graduação deverá ser elaborado integralmente o que estabelece a Resolução no 05, de 10 de março de 1983, do Conselho Federal de Educação e normas da CAPES. O Art. 6o Os cursos de Mestrado e Doutorado deverão ser designados de acordo com o que estabelece o parecer no 977 , de 03 de dezembro de 1965, e a Resolução no 05, de 10 de março de 1983, do Conselho Federal de Educação.

4 A legislação interna da UFSM está descrita, conforme a linha do tempo, na obra de Scheneider, Rigues e Rodrigues (1997). Oferece ao público leitor a noção de como a pós-graduação foi se desenvolvendo ao longo dos anos e a necessidade de rever os documentos oficiais para dar conta das novas demandas vigentes.

Educação Por Escrito, Porto Alegre, v. 8, n. 2, p. 244-259, jul.-dez. 2017 
É curioso conhecer a história de implantação da pós-graduação na UFSM e como os programas e cursos foram se constituindo, pois no último ranking que considerou a quantidade de cursos de programas de pós-graduação no Brasil (PPGs), a UFSM ficou na 15a colocação, e em nível de Rio Grande do Sul conquistou a 2a colocação, ficando, somente, atrás da Universidade Federal do Rio Grande do Sul (UFRGS/PRPGP, 2017).

O primeiro curso de pós-graduação da UFSM foi criado em 1970, na área das Ciências Humanas, na Educação, em nível de mestrado, após 10 anos da criação dessa instituição. Em janeiro de 1991, iniciou-se o primeiro curso de doutorado, o Programa de Pós-Graduação em Ciências do Movimento Humano; e, em 2008, surgiu o primeiro curso de mestrado profissional no programa de Pós-Graduação em Patrimônio Cultural ${ }^{5}$.

Dentre as nove grandes áreas que compõem os 54 Programas de Pós-Graduação da UFSM, 55\% correspondem a 46 cursos em nível de mestrado acadêmico, $11 \%$ a nove cursos de mestrado profissional e $34 \%$ a 29 cursos de doutorado (UFSM, 2016).

O Gráfico 1, a diante, destaca as áreas de Ciências Agrárias, Ciências Biológicas, Ciências da Saúde, Ciências Exatas e da Terra, Ciências Humanas, Ciências Sociais e Aplicadas, Engenharias, Linguística, Letras e Artes e Multidisciplinar, de modo a quantificar o número de cursos de mestrado acadêmico, mestrado profissional e doutorado.

Ao analisar-se o Gráfico 1, percebe-se que o número de cursos se relaciona, considerando a linha do tempo em que foi acontecendo, à criação dos PPGs na UFSM e o maior número de cursos de mestrado e doutorado acadêmico se encontra nas áreas das Ciências Agrárias e Ciências da Saúde, enquanto no mestrado profissional a representação maior é na área das Ciências Humanas.

5 Dados extraídos da Plataforma Sucupira, em Dados Cadastrais do Programa, disponível em: <https://sucupira.capes.gov.br/sucupira/public/ consultas/coleta/programa/listaPrograma.jsf>. Acesso em: abr. 2016. 
Gráfico 1. Grandes áreas e seus respectivos programas de pós-graduação (UFSM)

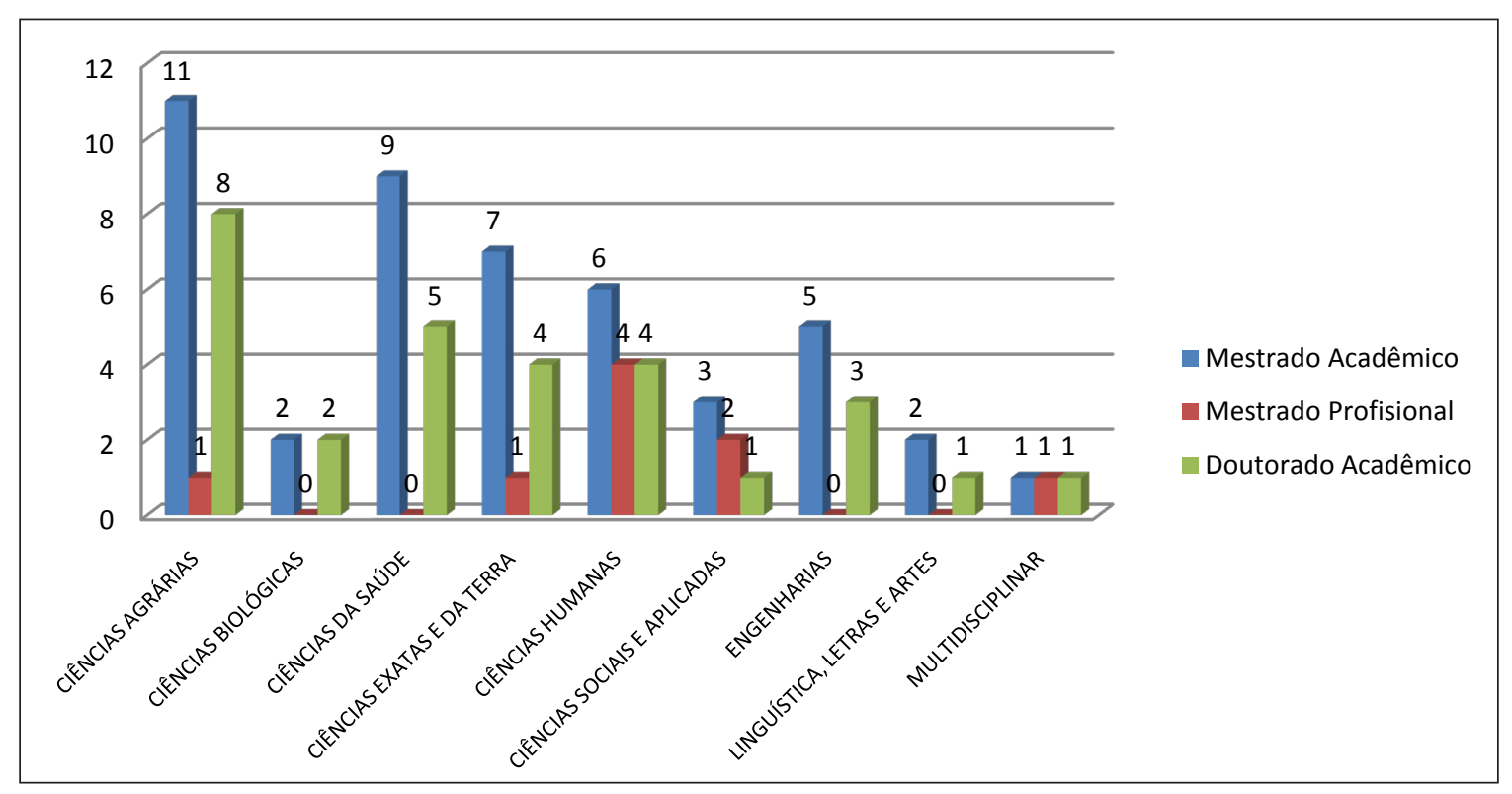

Fonte: Autoras (2016).

\section{Resultados e discussões}

É possível afirmar que, na linha do tempo de evolução dos Programas de Pós-Graduação da UFSM, em nível stricto sensu, houve um crescimento acelerado desde o primeiro curso criado. É relevante considerar que a linha de crescimento se manteve em ascensão no decorrer dos anos, com exceção de curtos períodos em que não houve a criação de novos cursos. O maior número de cursos criados foi em 1996, no mestrado acadêmico; em 1998, no doutorado acadêmico; e, em 2008, no mestrado profissional. Se forem analisados os cursos como um todo, o ápice do crescimento foi a partir de 2008, conforme Gráfico 2, a seguir: 
Gráfico 2. Evolução dos cursos de pós-graduação da UFSM (criação e desativação)

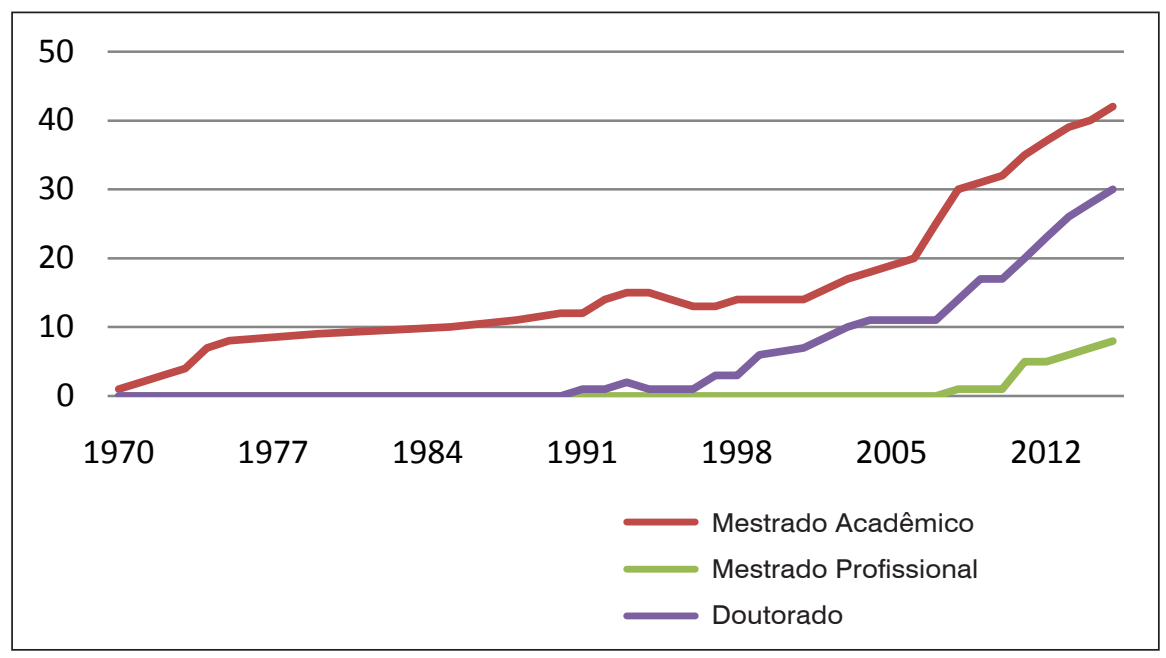

Fonte: Autoras (2016).

Muitos foram os fatores que implicaram a expansão dos PPGs da UFSM, tendo em vista o cenário de políticas externas e internas que acenaram para seu crescimento. Essa evolução não se limita somente à pós-graduação, pois a expansão na UFSM se deu como um todo, na criação de novos campi, de polos de educação a distância, bem como de novos cursos de graduação que somaram para a expansão dessa universidade.

É necessário fazer referência que a Capes corroborou para a evolução dos PPGs, tendo prestado um serviço de coordenação e aperfeiçoamento de pessoal de nível superior, expressando-se na expansão e consolidação de cursos e programas stricto sensu em todos os estados da federação. Na UFSM, essa iniciativa não foi diferente.

Por conseguinte, foram analisadas as atuais políticas internas e externas que investiram em um novo cenário da pós-graduação da UFSM em contextos emergentes. Nesse sentido, aponta-se que o próprio Plano de Gestão 2014-2017 da UFSM tem como filosofia a otimização de recursos disponíveis para alcançar os níveis de excelência no ensino, na pesquisa e na extensão. Essa mudança de visão encontra-se amparada no Plano de Desenvolvimento Institucional 2011-2015, que preconiza o processo de autoavaliação institucional e o projeto pedagógico da instituição, fatores 
críticos apontados na análise ambiental e princípios do Programa Nacional de Gestão Pública e Desburocratização - Gespública ${ }^{6}$.

Logo, percebe-se que a atual gestão 2014-2017 preconiza construir e difundir conhecimento, de modo a se comprometer com a formação de pessoas capazes de inovarem e contribuírem para o desenvolvimento da sociedade. Em razão disso, a PRPGP/UFSM vem trabalhando para envolver as comissões internas dos programas, no sentido de manter e fortalecer a qualidade dos cursos, bem como discutir políticas que antecedam a avaliação externa da Capes.

Outra medida, adotada pela PRPGP/UFSM, refere-se à manifestação de interesse em participar da cooperação internacional, tendo em vista potencializar experiências e informações de outros PPGs e desenvolver padrões internos de ensino e de pesquisa da UFSM que impliquem resolver problemas de interesse comum da sociedade. A internacionalização acadêmica é um dos elementos-chave que a Capes e o CNPQ vêm trabalhando com as universidades brasileiras e estrangeiras.

Diante desse apoio à pós-graduação, a universidade tem proporcionado aos acadêmicos, em nível stricto sensu, diferentes experiências internacionais que garantem a mobilidade e os intercâmbios dos pós-graduandos, através de programas de mobilidade acadêmica gestados na Secretaria de Apoio Internacional - SAI ${ }^{7}$.

Cabe ressaltar que, no corrente ano, 75 alunos de doutorado estão estudando no exterior, fruto do empenho e colaboração de políticas e investimentos internos e externos à UFSM. Sendo que a maior concentração de acadêmicos de doutorado da UFSM se encontra na França, nas modalidades de Cotutela ${ }^{8}$ e Dupla Formação (PRPGP, 2017). A UFSM também está engajada em receber estrangeiros para fazer doutorado pleno no Brasil. E firmou convênio com o Programa de Estudantes - Convênios de Pós-Graduação (PEC-PG) ${ }^{9}$, recebendo três estrangeiros do Paraguai

6 O Programa Gespública vem a ser um poderoso instrumento de cidadania, pois renova seu compromisso de engajamento e valorização das pessoas por meio de estratégias de mobilização da administração pública, contribuindo para a melhoria da qualidade dos serviços públicos prestados aos cidadãos e para o aumento da competitividade do país.

7 A SAI tem a função de assessorar e prestar informações sobre os convênios existentes, bem como promover intercâmbios internacionais, apresentando os cursos oferecidos pelas mais diversas instituições, tramitando documentos e recebendo registros dessas atividades, além de receber estudantes e docentes de outros países que participem de atividades acadêmicas como intercambistas.

8 A cotutela de dissertação e tese se refere à diplomação com titulação simultânea em dois países e foi regulamentada na UFSM pela Resolução no 024/2014.

9 Programa fruto de parceria entre a Coordenação de Aperfeiçoamento de Pessoal de Nível Superior (Capes), o Ministério das Relações Exteriores (MRE) por intermédio da Divisão de Temas Educacionais (DCE) e o Conselho Nacional de Desenvolvimento Científico e Tecnológico (CNPq). A primeira proposta de Acordo de Cooperação Educacional, Cultural ou de Ciência e Tecnologia iniciou-se em 2008, tendo a primeira chamada de candidatos em 2010. 
e da Venezuela em 2010, em nível de doutorado ${ }^{10}$; um estrangeiro da Venezuela, em 2012, no Programa de Pós-Graduação em Engenharia Agrícola; três estrangeiros de Moçambique, em 2013, nos Programas de PósGraduação em Educação, Letras e Meteorologia; e dois estrangeiros de Moçambique, em 2016, nos Programas de Pós-Graduação em Comunicação e Engenharia Elétrica (CAPES, 2017). É possível verificar que os estrangeiros procuram as mais diversas áreas do saber e que há uma grande quantidade de selecionados desde que o PECPG foi criado. Neste ano, no mês de abril, a Capes anunciou que foram selecionados mais 82 estrangeiros para cursar doutorado no Brasil (CAPES, 2017). O quantitativo demonstra que os acadêmicos, procedentes de países em desenvolvimento, com os quais o Brasil mantém acordo de cooperação educacional, cultural ou de ciência e tecnologia, têm interesse em realizar estudos de pós-graduação stricto sensu em instituições de ensino superior brasileiras.

Constata-se que a PRPGP continua seu processo de expansão, visando, cada vez mais, a garantir a qualidade e a ascensão dos PPGs da UFSM em nível nacional e internacional. A implementação da cotutela tem contribuído para esse processo e proporcionado um cenário para a internacionalização da pós-graduação, como um dos principais meios à melhoria da qualidade na formação de recursos humanos e da pesquisa gerada em PPGs.

Nessa conjuntura, a UFSM vem mantendo contato com a Unicamp, pois esta é uma instituição com forte inserção internacional. Essa ação é possível graças à elaboração de normativas para a cotutela de doutorandos de PPGs da UFSM com ou sem dupla titulação, em instituições estrangeiras (UFSM, 2013).

A UFSM possui acordos e parcerias com a Universidade Federal do Espírito Santo (Ufes) e com as universidades francesas Université, de Lorraine, e École dês Mines, de Nancy, com o objetivo de fomentar o intercâmbio de ideias e culturas e fortalecer o protagonismo da instituição. Além deste, estão sendo firmados ainda acordos com a Universidade de McGill, do Canadá, e convênios com universidades russas, que chamam a atenção para o desenvolvimento das áreas de tecnologia (UFSM, 2015).

Assim, ressalta-se que a UFSM vem explorando a internacionalização e a mobilidade acadêmica, de modo a proporcionar espaços de integração e troca de experiências entre representantes e profissionais da educação internacional, visando a globalizar o ensino e a pesquisa, por meio da integração de universidades e do intercâmbio de pessoas em outros países e, além disso, recebendo estudantes estrangeiros nos PPGs. Investimentos estão sendo aplicados a professores efetivos e a estudantes no desenvolvimento de pesquisa, pela concessão de bolsas acadêmicas de mestrado e doutorado, oriundas da Capes, CNPQ, Fapergs, entre os principais fomentos.

\footnotetext{
${ }^{10}$ No edital de resultado final não constam os Programas de Pós-graduação da UFSM em que os estrangeiros foram selecionados.
} 
Vale referir que a UFSM possui incentivos internos com recursos próprios, tais como o Programa Especial de Incentivo à Pesquisa para o Servidor Mestre (PEIPSM) ${ }^{11}$; o Programa de Fundo de Incentivo à Inovação Tecnológica (FIT) ${ }^{12}$; o Programa de Bolsas de Iniciação Científica ou Auxílio à Pesquisa Sênior ${ }^{13}$, Júnior $^{14}$ e $\operatorname{ARD}^{15}$ (Fipe); o Programa de Iniciação Científica para o Hospital Universitário de Santa Maria (Proic HUSM) ${ }^{16}$; o Programa Institucional de Bolsas de Iniciação Científica Tecnológica e Inovação (Fapergs/UFSM) - Probiti ${ }^{17}$; e o Programa Institucional de Bolsas de Iniciação Científica (Fapergs/UFSM) Probic $^{18}$.

Investimentos, de apoio externo, também contribuem para a manutenção, qualidade e expansão dos PPGs da UFSM, como o Pibic - Programa Institucional de Bolsas de Iniciação Científica (CNPq/UFSM) - e o Pibic Programa Institucional de Bolsas de Iniciação Científica - em Ensino Médio (CNPq/UFSM).

Em 2017, o Ministério da Educação liberou R\$ 316,25 milhões à Capes. Esse valor deverá custear aproximadamente 190 mil bolsas, em diversos programas, além de apoiar a realização de eventos científicos e de atividades de pesquisa em programas estratégicos. Também a PRPGP/UFSM recebeu recursos financeiros via Programa de Apoio à Pós-Graduação (Proap), por meio da Portaria no 156/2014, que estabelece a alocação dos recursos e as despesas que poderão ser custeadas, como materiais para custeio e manutenção de

${ }^{11}$ Concessão de Bolsas de Iniciação Científica ou Auxílio à Pesquisa do "Programa Especial de Incentivo à Pesquisa para o Servidor Mestre", que se destina aos servidores "mestres" da UFSM que obtiveram o título de Mestre após 1 de janeiro de 2012, ou que estão em período de estágio probatório na UFSM (ingressado na UFSM após 1o de janeiro de 2014), ou ainda que estiverem matriculados em curso de doutorado oferecido pela UFSM.

${ }^{12}$ Concessão de Auxílio Integrado à Inovação Tecnológica, composto de Bolsa de Iniciação à Inovação Tecnológica (BIT) e Auxílio à Inovação, vinculado ao Fundo de Incentivo à Inovação Tecnológica.

${ }^{13}$ Concessão de Bolsas de Iniciação Científica e Auxílio à Pesquisa do Fundo de Incentivo à Pesquisa que se destina aos servidores com conclusão de doutorado em data anterior a 1o de janeiro de 2012 (Fipe Sênior).

${ }^{14}$ Concessão de Bolsas de Iniciação Científica e Auxílio à Pesquisa do Fundo de Incentivo à Pesquisa, que se destina aos servidores com conclusão de doutorado em data posterior a 01 de janeiro de 2012 (FIPE Júnior).

${ }^{15}$ Concessão de auxílio à pesquisa de recém-doutores, que se destina aos servidores doutores da UFSM com conclusão de doutorado em data posterior a 10 de janeiro de 2012.

${ }^{16}$ Concessão de Bolsas de Iniciação Científica e Auxílio à Pesquisa do programa para os grupos que desenvolvem ações de pesquisa no âmbito do Hospital Universitário de Santa Maria - HUSM.

${ }^{17}$ Programa de concessão de bolsas de iniciação em desenvolvimento tecnológico e inovação que visa a estimular estudantes do ensino técnico e superior ao desenvolvimento e transferência de novas tecnologias e inovação.

${ }^{18}$ Programa de concessão de bolsas de iniciação científica vinculado à Fapergs, voltado para o desenvolvimento do pensamento científico e iniciação à pesquisa de estudantes de graduação do ensino superior do RS. 
programas, além de expansão de materiais bibliográficos e acervo para periódico. Há, também, incentivo para que os estudantes e professores participem de eventos para divulgação e publicização de resultados dos estudos em desenvolvimento e realização de eventos científico-acadêmicos no país e no exterior. Além disso, a UFSM destina recursos para incentivo a atividades de intercâmbio e parcerias entre PPGs e manutenção de tecnologias em informática.

Outro passo à expansão foi feito através, da Resolução no 02/2005, que instituiu e regulamentou o Programa de Pós-Doutorado na UFSM. Essa resolução estabelece vagas a pessoas portadoras do título de doutor, não servidores da UFSM, em atividades de pesquisa com prazo delimitado, em Programas de Pós-Graduação com nível de doutorado recomendados pelas Capes, há pelo menos dois anos, ou com conceito 4 ou superior (UFSM, 2005). Segundo a PRPGP/UFSM, todas as bolsas concedidas são de fomento externo, via Programa de Apoio a Projetos Institucionais com a Participação de Recém-Doutores (Prodoc), com ofertas de bolsas de pós-doutoramento no valor mensal de $\mathrm{R} \$ 3.000,00$ e auxílio financeiro anual de R \$12.000,00, para custeio de atividades de ensino, pesquisa e extensão, referentes ao projeto apoiado (CAPES, 2005).

Em meio a todas essas políticas e investimentos que corroboraram para a expansão da pós-graduação da UFSM, a partir de 2014, a realidade desse cenário começou a apresentar uma redução na criação de novos cursos stricto sensu. A expectativa para os próximos anos implica que o crescimento dos programas de pós-graduação seja mínimo, tendo em vista as políticas criteriosas da Capes e o objetivo da UFSM de garantir e promover a qualidade dos cursos e o reconhecimento em nível nacional e internacional.

Verifica-se que, a cada 10 projetos de implantação de cursos novos enviados à Capes, apenas três estão sendo aceitos e aprovados, ou seja, o percentual é de 3,33\% (PRPGP/UFSM, 2017). Essa realidade se justifica em face de a Capes ter como objetivo assegurar e manter a qualidade dos cursos existentes de mestrado e doutorado e ser referência para a distribuição de bolsas e recursos para o fomento à pesquisa.

Assim, a PRPGP/UFSM, ao fazer a leitura desse cenário de exigências da Capes, projetou em 2014 novas políticas de gestão e acenou para a expectativa do reduzido crescimento em cursos de pós-graduação. Visou a oferecer qualidade aos cursos existentes e a tornar a UFSM reconhecida como uma instituição de excelência na construção e difusão do conhecimento, comprometida com o desenvolvimento da sociedade, de modo inovador e sustentável (UFSM, 2014).

A desaceleração da expansão da pós-graduação se justifica, também, pela redução drástica no orçamento para investimentos e custeios de toda a estrutura e organização da UFSM. Em 2014, o corte em investimentos foi de 59\%. No ano seguinte, o índice foi de 46\%. E, em 2016, o contingenciamento foi ligeiramente menor: 37\%. Este ano, tem previsão de amargar com uma redução de 45\%. No orçamento geral, em 2016, a UFSM fechou com R\$1,05 bilhão 
executados. Desse valor, mais de $80 \%$ é para pagamento de pessoal, sendo R $\$ 875$ milhões com salários e benefícios. O restante é investimento e custeio. Para 2017, o orçamento projetado é de R\$ 1,1 bilhão (UFSM, 2017), mas pode ser menor.

Constata-se que são diversas as variáveis que indicam a diminuição da expansão dos cursos de pós-graduação da UFSM, considerando o atual cenário das políticas federais e a reorganização da gestão em prezar pela qualidade e consolidação destes e seu reconhecimento em nível nacional e internacional.

\section{Considerações finais}

Estudar a expansão da pós-graduação da UFSM é um grande desafio para a comunidade acadêmica, pois retrata um cenário de evoluções da ciência e de um contexto regiona que anseia, cada vez mais, ganhar prestígio em nível nacional e internacional. Também marca os anseios de uma época, de um grupo de pessoas e de evoluções de políticas públicas voltadas à inserção de uma prática científica de qualidade nas grandes áreas do saber.

A organização da economia mundial que deu enfoque às instituições nas grandes cidades da região Sul, na última década, implicou a expansão da pós-graduação da UFSM, através da maturação das ações estratégicas internas da própria instituição, que culminaram no desenvolvimento de seus programas e cursos.

Foi constatado que, no período de 1970 a 2016, a linha de crescimento da pós-graduação da UFSM se manteve em ascensão, principalmente nas últimas décadas, com exceção de curtos períodos em que não houve a criação de novos cursos. O maior crescimento de cursos stricto sensu teve representatividade a partir de 2008.

Muitos foram os fatores que promoveram a expansão dos PPGs da UFSM, tendo em vista o cenário de políticas externas e internas que acenaram para seu crescimento: a nova filosofia do Plano de Gestão 2014-2017 da UFSM que visa à otimização de recursos disponíveis para alcançar os níveis de excelência no ensino, na pesquisa, na extensão e na gestão; o envolvimento de comissões internas dos programas, no sentido de manter e fortalecer a qualidade dos cursos, bem como discutir políticas que antecedam a avaliação externa da Capes; a participação da cooperação internacional e nacional, tendo em vista potencializar experiências e informações de outros PPGs e desenvolver padrões internos de ensino e pesquisa da UFSM; e o intercâmbio de pessoas a outros países, assim como receber estrangeiros nos Programas de Pós-Graduação da UFSM.

Nesse sentido, entende-se que os PPGs da UFSM necessitam atingir a excelência em seu campo, e que esse reconhecimento se estenda a outros programas, por meio de acordos e parcerias que visem a consolidar papéis sociais da universidade e para a relevância na pesquisa e no ensino, em âmbito nacional e internacional. 
Desse modo, a expectativa para os próximos anos implica que o crescimento dos PPGs da UFSM seja mínimo, por conta das políticas rigorosas da Capes e do objetivo da UFSM de garantir e promover a qualidade dos cursos e o seu prestígio nacional e internacional, tendo em vista a frequente redução de recursos financeiros repassados às universidades federais.

Assim, o cenário apresentado sobre a expansão da pós-graduação da UFSM demonstrou, ao longo dos anos, que as novas demandas implicadas pelos contextos emergentes influenciaram no plano de gestão da PRPGP, com o objetivo de contemplar as metas vigentes no ensino, na pesquisa e na extensão. Conclui-se que, com as novas configurações que emanam dos contextos emergentes, a UFSM e as demais instituições de ensino federais terão de definir novas diretrizes e estratégias para dar continuidade aos PPGs e acenar para a qualidade da pesquisa no Brasil.

\section{Referências}

BRASIL. Ministério da Educação e Cultura. A democratização e expansão da educação superior no país 2003-2014. Sesu. Disponível em: <http://portal.mec.gov.br/index.php?option=com_docman\&view=download\&alias=16762-balanco-social-sesu-20032014\&Itemid=30192>. Acesso em: 24 abr. 2016.

CAPES. Plataforma Sucupira. Acesso Programas de Pós-Graduação da UFSM. Disponível em: <https://sucupira.capes.gov.br/ sucupira/public/consultas/coleta/docente/listaDocente.jsf>. Acesso em: 24 abr. 2016.

. Programa de Estudantes. Convênio de Pós-Graduação (PEC-PG). Resultado Final Capes/PEC-PG Doutorado Edital no 23/2016. Disponível em: <http://www.capes.gov.br/images/stories/download/editais/resultados/26042017-Edital-23-2016-PEC-PGResultado-final.pdf>. Acesso em: 25 abr. 2016.

Programa de Estudantes. Convênio de Pós-Graduação (PEC-PG). Resultado Final Capes/PEC-PG Doutorado Edital no 62/2013. Disponível em: <http://www.capes.gov.br/images/stories/download/editais/resultados/Resultado_PECPG_62_2013_ Retificacao.pdf>. Acesso em: 25 abr. 2016.

Programa de Estudantes. Convênio de Pós-Graduação (PEC-PG). Resultado Final Capes/PEC-PG Doutorado Edital no $42 / 2012$. Disponível em: <http://www.capes.gov.br/images/stories/download/editais/resultados/ResultadoFinal-Edital_42-2012_PECPG.pdf>. Acesso em: 26 abr. 2016.

. Programa de Estudantes. Convênio de Pós-Graduação (PEC-PG). Resultado Final Capes/PEC-PG Doutorado Edital no 48/2010. Disponível em: <http://www.capes.gov.br/images/stories/download/editais/resultados/PECPG_Edital48_2010_ListaFinal Retificada02.pdf>. Acesso em: 27 abr. 2016.

BOLZAN, D. P. V. Docência e processos formativos: estudantes e professores em contextos emergentes. Projeto de Pesquisa. Universal - MCTI/CNPq no 01/2016. UFSM, 2016. 
FREITAS, M. T. de A. A abordagem sócio-histórica como orientadora da pesquisa qualitativa. Faculdade de Educação da Universidade Federal de Juiz de Fora. Cadernos de Pesquisa, no 116, jul. 2002.

GATTI, B. A. Estudos qualitativos em educação, São Paulo, v. 30, n. 1, p. 11-30, jan./abr. 2004. Disponível em: <http:// http://www. scielo.br/pdf/ep/v30n1/a02v30n1.pdf>. Acesso em: 12 jul. 2017.

GUTERRES, C. R. J. Reflexões sobre a Pós-Graduação em Educação no Rio Grande do Sul. Conjectura: Filos. Educ., Caxias do Sul, v. 18, n. especial, p. 17-32, 2013, Disponível em: <http://www.ucs.br/etc/revistas/index.php/conjectura/article/viewFile/2098/pdf_185>. Acesso em: 5 set. 2016.

LUDKE, Menga; ANDRÉ, Marli. Pesquisa em educação: abordagens Qualitativas. São Paulo, EPU, 1986.

MOROSINI, M. C. Qualidade da educação superior e contextos emergentes. Avaliação, Campinas: Sorocaba, SP, v. 19, n. 2, p. 385-405, jul. 2014. Disponível em: <http:www.scielo.br/pdf/aval/v19n2/a07v19n2.pdf>. Acesso em: 18 jul. 2016.

PEDRINI, M. A educação brasileira e a formação de professores. In: FRANCO, M. E. D. P.; MOROSINI, M. C. (Org.). Qualidade da educação superior: dimensões e indicadores. Porto Alegre: EdiPUCRS, 2011, Vol. 4. 672 p.

RIES. Indicadores de qualidade para a educação superior brasileira. 2013.

SCHENEIDER, P. R.; RIGUES, A. A.; RODRIGUES, M. B. Coletânea de legislação de pós-graduação. Pró-Reitoria de Pós-Graduação e Pesquisa. Santa Maria: Biblioteca Central da UFSM, 1997.

UFSM. Resolução no 002/2005. Institui o Programa de Pós-Doutorado na Universidade Federal de Santa Maria. Disponível em: < http:// prpgp.ufsm.br/images/fomularios-diversos/arq_resolu_o_n_2005_002_153.pdf>. Acesso em: 10 maio 2017.

. Pró-Reitoria de Pós-Graduação e Pesquisa. Editais internos - 2017. Disponível em: <http://prpgp.ufsm.br/editais/editaisinternos $>$. Acesso em: 12 maio 2017.

Cursos de mestrado e doutorado. PRPGP: Disponível em: < http://prpgp.ufsm.br/pos-graduacao/cursos-de-mestrado-

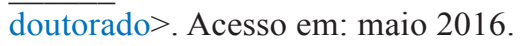

. Notícias da UFSM. Foco na internacionalização. Publicado em 03 jun. 2015. Disponível em: <http://site.ufsm.br/noticias/ exibir/foco-na-internacionalizacao>. Acesso em: 13 ago. 2017.

. Dados do quadro docente da UFSM. Progep: mar. 2016. $\overline{\operatorname{mar} .2016}$

. Dados históricos da UFSM. Disponível em: <http://w3.ufsm.br/frederico/index.php/institucional/historico>. Acesso em: 23

. Guia do estudante 2016. Disponível em: $<$ http://w3.ufsm.br/prograd/index.php/documentos/guia-do-estudante-ufsm>. Acesso em: 2 maio 2016.

. UFSM na Mídia. Clipping de notícias sobre a educação e a UFSM. Disponível em: <http:// http://coral.ufsm.br/ $\overline{\text { midia/? }} \mathrm{p}=37440>$. Acesso em: 14 maio 2017.

MAY, Tim. Pesquisa social: questões, métodos e processos. 3. ed. Porto Alegre: Artmed, 2004. 
SEVERINO, A. J. Metodologia do trabalho científico. São Paulo: Cortez, 2007.

UNESCO. Educação. Disponível em: <http://nacoesunidas.org/agencia/unesco/>. Acesso em: 18 jun. 2016.

VYGOTSKI, L.S. Obras escogidas. Tomo I. Machado Grupo de Distribución: Madrid, 1991.

Recebido em: setembro/2017

Aceito em: outubro/2017

Endereço para correspondência:

Av. Roraima, 1000 - Camobi

97105-900 Santa Maria, RS, Brasil

<silvanazancan@hotmail.com> 